\title{
Physical activity and Baltic Sea diet are interactively related to higher life satisfaction in community-living older Finnish women: OSTPRE-FPS study
}

\author{
Masoud Isanejad ${ }^{1,2 *}$, Heli Koivumaa-Honkanen ${ }^{3,4}$, Diana Ruiz de Santiago $^{2}$, Risto Honkanen ${ }^{5}$, \\ Toni Rikkonen ${ }^{2}$, Joonas Sirola ${ }^{2,5}$, Heikki Kröger ${ }^{5}$ and Arja T. Erkkilä \\ ${ }^{1}$ Institute of Ageing \& Chronic Disease, University of Liverpool, Liverpool L6 8TX, UK \\ ${ }^{2}$ Kuopio Musculoskeletal Research Unit, University of Eastern Finland, FI-70211 Kuopio, Finland \\ ${ }^{3}$ Department of Psychiatry, University of Eastern Finland, P.O. Box 1627, Kuopio, Finland \\ ${ }^{4}$ Departments of Psychiatry: Kuopio University Hospital, Kuopio, Finland; and South-Savonia Hospital District, Mikkeli, Finland \\ ${ }^{5}$ Department of Orthopaedics and Traumatology, Kuopio University Hospital, FI-70211 Kuopio, Finland \\ ${ }^{6}$ Institute of Public Health and Clinical Nutrition, University of Eastern Finland, FI-70211 Kuopio, Finland \\ (Submitted 18 January 2019 - Final revision received 6 September 2019 - Accepted 10 September 2019)
}

\begin{abstract}
A healthful diet and sufficient physical activity (PA) are related to several health outcomes. However, there is a paucity of data on the association of PA and dietary pattern with life satisfaction (LS) in the older adults aged $\geq 65$. The present study investigated the independent and combined association of PA and Baltic Sea diet (BSD) score with LS in older Finnish women. Subjects were 554 women aged 65-72 years from the Osteoporosis Risk Factor and Prevention - Fracture Prevention Study. Women reported the hours and type of PA and lifestyle factors via questionnaires and dietary intake using the 3 - $\mathrm{d}$ food record. Adequate $\mathrm{PA}$ was considered according to WHO recommendation: $\mathrm{PA}=0,0<\mathrm{PA}<2.5$ and $\geq 2 \cdot 5 \mathrm{~h}$ /week. BSD score was categorised as $<13$ or $\geq 13$ based on the median score. LS was self-reported using LS scale with four items on current 'interest', 'happiness in life', 'ease of living' and 'feelings of loneliness' (range: 4-20, lower score representing higher satisfaction). After adjusting for the confounders, PA was statistically significantly associated with lower LS score $(\beta$ coefficient $=-0 \cdot 207, P=0 \cdot 001)$, where women with $\mathrm{PA} \geq 2.5 \mathrm{~h} /$ week had the lowest LS score followed by women with $0<\mathrm{PA}<2.5$ and $\mathrm{PA}=0\left(P_{\mathrm{for} \text { trend }}=0.020\right)$. Association between BSD and LS was NS. Only among women with BSD score $\geq 13$, but not $\mathrm{BSD}<13$, PA $\geq 2.5 \mathrm{~h} /$ week was statistically significantly associated with lower LS score $($ mean $=9 \cdot 3)$, followed by $0<\mathrm{PA}<2.5($ mean $=9.9)$ and PA $=0$ groups $($ mean $=11 \cdot 8)\left(P_{\text {for trend }}=0 \cdot 033\right)$. In conclusion, adequate $\mathrm{PA}$ according to WHO recommendation independently and in combination with higher BSD score may be associated with higher LS in older women.
\end{abstract}

Key words: Physical activity: Diet quality: Subjective well-being: Older adults

Most of the developed countries have unified the definition of 'elderly' or 'older person' for chronological age of 65 years and above $^{(1)}$. Nowadays this group of older people is experiencing greater longevity and has an increasing presence among the community in Europe ${ }^{(2,3)}$. Their subjective well-being has faced a significant increase in importance along with the concept of healthy ageing. It has been suggested that a high level of subjective well-being is associated with a decreased mortality and increased life expectancy ${ }^{(4,5)}$. In this context, life satisfaction (LS) was further introduced as an indicator of subjective well-being and quality of life ${ }^{(6)}$. Different assessment tools have been used to reflect the LS in older adults. In previous studies, where LS status was derived by a four-item self-reported LS scale, it has been shown that life dissatisfaction has been associated with different adverse health predictors, such as poor health behaviour, self-reported morbidity ${ }^{(7)}$ and low social support ${ }^{(8)}$ as well as to be an independent predictor of psychiatric morbidity among general population ${ }^{(9,10)}$. Life dissatisfaction also predicted major depressive disorders and poor mental health ${ }^{(8,10)}$, morbidity, mortality, psychiatric and somatic disability ${ }^{(10)}$. In an interview, women who answered one-item question on LS of being unsatisfied had increased risk of cancer, stroke and type 2 diabetes compared with women who were very satisfied with life ${ }^{(11)}$.

Abbreviations: BSD, Baltic Sea diet; LS, life satisfaction; OSTPRE-FPS, Osteoporosis Risk Factor and Prevention - Fracture Prevention Study; PA, physical activity.

* Corresponding author: Masoud Isanejad, email m.isanejad@liverpool.ac.uk 
Although there is much discussion on the factors that determine $\mathrm{LS}^{(12,13)}$, relatively little scientific evidence is available regarding the association of modifiable factors such as physical activity (PA) and diet with LS in older adults. Some evidence suggests that chronic illnesses are related to low LS, affective well-being and quality of life in old age ${ }^{(14)}$. Thus, PA interventions could represent an effective behavioural strategy for mental health and enhance the quality of life in older adults ${ }^{(15,16)}$. However, to our knowledge studies that have assessed the relation of PA and LS in older adults are scarce. According to WHO recommendation, older adults ( 65 years and older) should have PA of at least $2.5 \mathrm{~h} /$ week in order to prevent physical function decline ${ }^{(17)}$.

In addition, consuming varied diet is important for older adults to obtain all the nutrients needed to achieve good physical and mental health and reduced mortality ${ }^{(18,19)}$. In older adults, higher diet quality has been linked with various health outcomes, including reduced risk of chronic disease, age-related diseases, which potentially results in longevity ${ }^{(20,21)}$. In prospective studies, a potential protective role of diet quality against depressive symptoms has been suggested ${ }^{(22,23)}$. In a crosssectional study, men with high adherence to Baltic Sea diet (BSD) were $40 \%$ more likely than men with low adherence to be nondepressed ${ }^{(24)}$.

The Baltic Sea dietary pattern was introduced in 2013 to characterise healthy Nordic diet (Kanerva et al. 2013). A dietary score represents a summary value of consumed foods or nutrients and characterises a measure of a predefined (healthy) diet ${ }^{(25)}$. Higher scores indicate better dietary quality and a higher intake of beneficial foods such as whole grains, vegetables, fruits and fish ${ }^{(25)}$. BSD pattern includes healthy foods such as apples and berries, roots and cabbage, rye, oats and barley, low-fat dairy products, rapeseed oil and fish (e.g. salmon and Baltic herring) typically consumed in the Nordic countries, but it is low in processed meat, red meat and alcohol ${ }^{(26)}$. According to the National FINRISK 2007 study, BSD was inversely associated with abdominal obesity among Finnish men ${ }^{(26)}$. In Finnish women aged 65-72 years, BSD was associated with better overall physical performance ${ }^{(27)}$. However, there is paucity of data regarding the association of BSD with LS, and previous studies have focused on the association of dietary patterns and depression. The findings of a cross-sectional study design by Lengyel et al. suggested that the daily consumption of vegetables and fruits was associated with better self-rated health and greater $\mathrm{LS}^{(28)}$. Thus, it would be tempting to hypothesise that a healthy diet such as BSD may be associated with higher LS (and better subjective well-being). The objective of the present study was to evaluate both the independent and the combined association of PA and BSD with LS in older women.

\section{Methods \\ Study population}

Data of the present study were collected from the Osteoporosis Risk Factor and Prevention - Fracture Prevention Study (OSTPRE-FPS) ( $n 750$ ), which was a 3-year intervention to investigate the effect of $\mathrm{Ca}$ and vitamin $\mathrm{D}$ supplementation on the incidence of falls and fractures among older women. The subjects were selected from the Finnish population-based OSTPRE cohort $(n 13100)^{(29)}$. The inclusion criteria for the present study were similar to OSTPRE-FPS, which were age at a minimum of 65 years at the end of November 2002, living in the Kuopio Province at the onset of the trial, not belonging to the former OSTPRE bone densitometry sample and living in community. The willingness to participate in a $\mathrm{Ca}$ and vitamin D trial was enquired via a postal enquiry between August and December 2002. Of the 5407 volunteers, 3432 (63.5\%) were randomised into two groups of equal size without stratification or random allocation sequence by an independent statistician. The subjects were assigned to their groups by postal notification according to the randomisation. OSTPRE-FPS was conducted as an open-label trial. In total, 3432 women volunteered to participate in the study, and 750 women were randomly invited into this subsample for participating in detailed examinations including measurement of body composition, clinical and physical examinations and laboratory tests. The measurements took place between February 2003 and May 2004.

Data for PA from the self-reported questionnaire were available for 608 women, of which LS data were available for 562 (missing data due to selecting more than one answer). Data for BSD score components were available for 510 women (missing data due to not returning or answering the separate alcohol consumption questionnaire, which results in missing value for some BSD food components).

All clinical measurements were performed in Kuopio Musculoskeletal Research Unit of the Clinical Research Center, University of Kuopio. All participants provided written consent. The study was approved in October 2001 by the ethical committee of Kuopio University Hospital. The study was registered in Clinical trials.gov by the identification NCT00592917.

\section{Dietary intake}

Dietary intake was assessed using a 3-d food record based on the amount of food consumed. The questionnaire and the instructions were sent to participants beforehand and were returned on the visiting day. The 3-d food record questionnaire was collected for three consecutive days including $1 \mathrm{~d}$ in the weekend (Saturday or Sunday). In case of uncertainties in the food record, a nutritionist called the participant for additional information $^{(30)}$. Underreporting has previously been reported and none of the participants was excluded due to low energy intake ${ }^{(30)}$. Consumption of food and the intake of nutrients were calculated using Nutrica program (version 2.5; Finnish Social Insurance Institute).

\section{Baltic Sea diet score}

The detailed calculation for BSD score has been explained previously in this article ${ }^{(31)}$. The BSD score consisted of nine components, of which five were food or food groups and four nutrient intake. The BSD score included positive components: (1) fruits and berries, (2) vegetables (root vegetables, legumes, nuts, mushrooms and vegetable products - potatoes excluded), (3) fibre from cereal products, (4) low-fat milk (skimmed milk and milk with fat content less than $2 \%$ ) and (5) total fish intake 
and a negative component (6) processed meat products (sausage), (7) total fat intake was expressed as a percentage of total energy intake (E \%), (8) quality of fat intake was represented by calculating a ratio of PUFA and SFA. (9) Frequency of consumption of alcohol portions ( 1 portion $=12 \mathrm{~g}$ ) was asked in a separate questionnaire. Construction of BSD score is summarised in online Supplementary Table S1. To calculate the BSD score, subjects were categorised into quartiles according to the BSD score components. For the positive components, 0 score was given to the lowest quartile, and a score of 3 was given to the highest quartile $(\mathrm{Q} 1=0, \mathrm{Q} 2=1, \mathrm{Q} 3=2, \mathrm{Q} 4=3)$, scorings for negative components were reversed. For alcohol consumption, if alcohol intake was $\leq 12 \mathrm{~g} / \mathrm{d}$, a score of 1 was assigned, else 0 score. BSD score ranged from 0 to 25 , higher points indicating higher adherence to BSD. Further, the BSD median intake $(\mathrm{BSD}<13 v . \mathrm{BSD} \geq 13)$ was used as to create dichotomic variable and a balance number of women in each group.

\section{Physical activity}

PA data were collected via a self-administered questionnaire where participants were asked to report the type, hours and seasonality (winter and summer) of their PA. Types of PA included walking, cycling, skiing, swimming, aerobic exercise, sport balls, skating, floor ball, gymnastics and rowing. Weekly amount of PA in winter and summer were calculated and the average was used as an estimate of long-term PA. For further categorical analyses, we used the cut-off adapted according to WHO recommendations for the amount of PA per week in older adults ${ }^{(17)}$. Women were categorised into $\mathrm{PA}=0 \mathrm{~h} /$ week, $0<\mathrm{PA}<2.5 \mathrm{~h} /$ week and $\mathrm{PA} \geq 2.5 \mathrm{~h} /$ week. We have also introduced a continuous variable of PA as per 1-unit increase.

\section{Life satisfaction}

The main outcome of the present study is LS, which was previously strongly linked with depressive symptoms ${ }^{(8)}$. It has also identified those with increased risk of several adverse health outcomes such as mortality ${ }^{(9)}$, suicide ${ }^{(32)}$ and both psychiatric and somatic disability ${ }^{(33,34)}$. In brief, the scale assesses current interest and happiness in life, ease of living and feeling of loneliness ranging from 1 ('very') to 5 ('not at all') except for loneliness which ranges from 1 to 4 , and it was reversed before computation of the sum of the LS score ${ }^{(35)}$.

\section{Confounders}

Data regarding lifestyle were self-reported, such as income per month (euros), marital status (married, divorced, widowed and not married), smoking status (never, past and current), medical history, medications (including hormone therapy) and time since menopause ${ }^{(36)}$. We defined multi-morbidity as the presence of two or more of chronic conditions, including hypertension, hyperlipidaemia, CHD, diabetes, arthritis, osteoporosis, depression, chronic kidney disease and cancer. Height and weight were measured with participants wearing light indoor clothing without shoes, and BMI was calculated $\left(\mathrm{kg} / \mathrm{m}^{2}\right)$. Mobility was defined as normal if women were (a) fully capable of moving, (b) capable of moving but unable to run or (c) capable of walking $1 \mathrm{~km}$ at the most. It was defined as restricted when women were (a) capable of walking $100 \mathrm{~m}$ at the most, (b) moving only indoors or (c) incapable of moving.

\section{Statistical analysis}

Characteristics were compared with LS score quartile categories using Pearson's $\chi^{2}$ test for categorical variables and ANOVA for continuous variables. ANOVA was used for testing the LS in the BSD categories according to median score (BSD median score $=13$ ) and three groups of PA. We calculated the standardised $\beta$ coefficient by testing the regression of PA and BSD with LS score. An interaction term between BSD and PA was introduced into regression analyses with LS as an outcome, and the association was statistically significant in both unadjusted $(P=0.010)$ and adjusted $(P=0.003)$ models. PA was categorised into three groups as explained above. In addition, to include a balanced number of participants and ensure the statistical power, we used the median BSD score $(=13)$ in the categorical analyses.

The $P_{\text {for trend }}$ was calculated on a linear trend across PA and BSD interaction groups using the median value in each category as a continuous variable in a multivariable linear regression analysis with LS as continuous dependent variable. Further, univariate ANOVA was conducted to calculate means and standard deviations for LS across the BSD and PA interaction groups.

Analyses were adjusted for age (years) and energy intake $(\mathrm{kJ} / \mathrm{d})$, BMI $\left(\mathrm{kg} / \mathrm{m}^{2}\right)$, PA (h/week) (only when BSD was set as exposure), years since menopause, smoking status (current smoker), mobility status (normal and restricted), income per month (euros), multi-morbidity and marital status. All statistical analyses were executed using SPSS software version 24 for windows (IBM Corp.). Differences were considered statistically significant if $P<0 \cdot 05$.

\section{Results}

Main characteristics of women according to LS score quartile are presented in Table 1. Women belonging to the highest quartile of LS score (dissatisfied) had lower PA (h/week), had lower alcohol consumption and were less likely to be current smokers. The main PA reported were skiing, walking, cycling, swimming and aerobic exercise, which explained over $90 \%$ of the weekly PA (data not shown), and accordingly they were used to compute the final PA variable in the present study.

Main characteristics are also presented according to PA and BSD groups (online Supplementary Tables S2 and S3). Women with $\mathrm{PA}=0 \mathrm{~h} /$ week $(n 77)$ had the highest BMI values and LS score but consumed less energy and protein when compared with their peers. Women with $\mathrm{PA} \geq 2.5 \mathrm{~h} /$ week had lower BMI, lowest LS score (satisfied) and highest BSD score, energy and protein intake. Those with at least median BSD score (BSD $\geq 13$ ) were more physically active and less often smokers.

We did not observe any statistically significant association between BSD as continuous variable or quartile categories with LS score (Table 2). In the analysis of continuous PA, we observed an inverse statistically significant association with 
Table 1. Characteristics and dietary factors of the participants according to life satisfaction (LS) score quartiles*

(Mean values and standard deviations; numbers and percentages)

\begin{tabular}{|c|c|c|c|c|c|}
\hline & $\begin{array}{c}\text { Quartile } \\
1, n 149 \\
(6-9)\end{array}$ & $\begin{array}{c}\text { Quartile 2, } \\
n 236 \\
(10-13)\end{array}$ & $\begin{array}{c}\text { Quartile } \\
3, n 55 \\
(14-16)\end{array}$ & $\begin{array}{c}\text { Quartile } \\
4, n 122 \\
(>16)\end{array}$ & $P$ \\
\hline $\begin{array}{l}\text { Physical activity } \\
\text { (h/week) }\end{array}$ & & & & & 0.016 \\
\hline Mean & 4.2 & 4.5 & 3.8 & 3.5 & \\
\hline SD & 1.4 & $1 \cdot 7$ & $1 \cdot 1$ & 1.3 & \\
\hline Age (years) & & & & & 0.110 \\
\hline Mean & 67.5 & 67.9 & $67 \cdot 6$ & 67.9 & \\
\hline SD & $1 \cdot 8$ & $1 \cdot 8$ & 1.8 & $1 \cdot 8$ & \\
\hline $\mathrm{BMI}\left(\mathrm{kg} / \mathrm{m}^{2}\right)$ & & & & & 0.311 \\
\hline Mean & $27 \cdot 4$ & $27 \cdot 3$ & $26 \cdot 7$ & 28.0 & \\
\hline SD & 4.0 & $4 \cdot 2$ & $4 \cdot 2$ & $4 \cdot 1$ & \\
\hline $\begin{array}{l}\text { Income (euros/ } \\
\text { month) }\end{array}$ & & & & & 0.059 \\
\hline Mean & 911 & 878 & 769 & 817 & \\
\hline SD & 252 & 329 & 231 & 300 & \\
\hline $\begin{array}{l}\text { Number of } \\
\text { chronic disease }\end{array}$ & & & & & 0.379 \\
\hline Mean & 1.5 & 1.4 & 1.2 & 1.5 & \\
\hline SD & 1.2 & 1.2 & 1.0 & $1 \cdot 1$ & \\
\hline $\begin{array}{l}\text { Restricted } \\
\text { mobility }\end{array}$ & & & & & 0.066 \\
\hline$n$ & 5 & 16 & 3 & 13 & \\
\hline$\%$ & 3.6 & $7 \cdot 2$ & $6 \cdot 4$ & $12 \cdot 5$ & \\
\hline Current smoker & & & & & 0.038 \\
\hline$n$ & 6 & 9 & 6 & 4 & \\
\hline$\%$ & $4 \cdot 3$ & $4 \cdot 1$ & $12 \cdot 5$ & 3.7 & \\
\hline $\begin{array}{l}\text { Current hormone } \\
\text { therapy }\end{array}$ & & & & & $0 \cdot 147$ \\
\hline$n$ & 39 & 51 & 8 & 18 & \\
\hline$\%$ & $27 \cdot 7$ & $22 \cdot 8$ & $16 \cdot 3$ & $16 \cdot 7$ & \\
\hline Currently married & & & & & 0.217 \\
\hline$n$ & 96 & 164 & 30 & 71 & \\
\hline$\%$ & $65 \cdot 3$ & 69.7 & 54.5 & 58.7 & \\
\hline \multicolumn{6}{|l|}{ Dietary factors } \\
\hline $\begin{array}{l}\text { Energy intake } \\
(\mathrm{kJ} / \mathrm{d})\end{array}$ & & & & & 0.515 \\
\hline Mean & 6543 & 6644 & 6322 & 6460 & \\
\hline SD & 1573 & 1464 & 1435 & 1744 & \\
\hline BSD score & & & & & 0.739 \\
\hline Mean & $12 \cdot 7$ & $13 \cdot 1$ & $13 \cdot 3$ & $12 \cdot 9$ & \\
\hline SD & $4 \cdot 1$ & $4 \cdot 2$ & $3 \cdot 2$ & 3.7 & \\
\hline Alcohol $(\mathrm{g} / \mathrm{d}) \dagger$ & & & & & 0.022 \\
\hline Mean & 11.9 & 11.5 & 7.7 & $6 \cdot 1$ & \\
\hline SD & $16 \cdot 6$ & $19 \cdot 7$ & $10 \cdot 7$ & $12 \cdot 1$ & \\
\hline Protein $(\mathrm{g} / \mathrm{d}) \ddagger$ & & & & & 0.738 \\
\hline Mean & $68 \cdot 7$ & 68.6 & $66 \cdot 7$ & $66 \cdot 7$ & \\
\hline SD & $18 \cdot 1$ & $16 \cdot 7$ & $15 \cdot 7$ & $20 \cdot 9$ & \\
\hline $\begin{array}{l}\text { Carbohydrate } \\
(\mathrm{g} / \mathrm{d}) \ddagger\end{array}$ & & & & & $0 \cdot 711$ \\
\hline Mean & 193.5 & $196 \cdot 3$ & 185.6 & $190 \cdot 9$ & \\
\hline $\mathrm{SD}$ & 49.1 & $47 \cdot 4$ & $42 \cdot 6$ & 53.3 & \\
\hline Fat $(g / d) \ddagger$ & & & & & 0.505 \\
\hline Mean & 53.2 & 54.9 & 52.0 & 53.7 & \\
\hline SD & $16 \cdot 6$ & 17.9 & $17 \cdot 1$ & $20 \cdot 3$ & \\
\hline
\end{tabular}

BSD, Baltic Sea diet.

* Characteristics were compared according to LS quartile as the outcome using Pearson's $\chi^{2}$ test for categorical variables and ANOVA for continuous variables.

† Alcohol consumption as $\mathrm{g} / \mathrm{d}$ was computed using the original variable, which was

based on portions per $\mathrm{d}$, where one portion was calculated as $12 \mathrm{~g}$ alcohol.

$\ddagger$ All macronutrients are energy adjusted.

LS score $\left(\beta\right.$ coefficient $=-0 \cdot 207$, sE $=0.037$ and $P_{\text {for } \text { trend }}=$ 0.001). The univariate ANOVA subjects with $\mathrm{PA} \geq 2.5 \mathrm{~h} /$ week showed statistically significant lower LS score $($ mean $=9 \cdot 4)$ followed by $0<\mathrm{PA}<2 \cdot 5$ (mean $=10 \cdot 3)$ and $\mathrm{PA}=0$ groups $($ mean $=10 \cdot 8)\left(P_{\text {for trend }}=0 \cdot 020\right)($ Fig. 1$)$.

\section{Interaction of Baltic Sea diet and physical activity with life satisfaction}

The interaction of PA and BSD was statistically significantly associated with lower LS score $(P=0.010$ and full adjusted $P=0.003$ ) (Table 2 ). Among women with BSD score $\geq 13$, those with $\mathrm{PA} \geq 2.5 \mathrm{~h} /$ week had statistically significantly lower LS score $($ mean $=9.3)$ followed by $0<\mathrm{PA}<2.5($ mean $=9.9)$ and $\mathrm{PA}=0$ groups $($ mean $=11 \cdot 8)\left(P_{\text {for trend }}=0.033\right)$. Whereas among women with BSD score $<13$, the association of PA with LS score was not statistically significant $\left(P_{\text {for trend }}=0 \cdot 069\right)($ Fig. 2$)$.

\section{Discussion}

As the population gets older, health outcomes such as LS become progressively more important. The present study is the first to evaluate the independent and combined association of PA and BSD with LS in older women. Women with PA $\geq 2.5$ had the lowest LS score (more satisfied) followed by $0<\mathrm{PA}<2.5$ and $\mathrm{PA}=0 \mathrm{~h} /$ week groups. We did not observe statistically significant association between BSD as continuous variable and LS. In the stratified analysis, we observed that women with $\mathrm{PA} \geq 2.5 \mathrm{~h} /$ week and $\mathrm{BSD} \geq 13$ (median) had the lowest LS score, while those with $\mathrm{PA}=0 \mathrm{~h} /$ week and $\mathrm{BSD}<13$ had the highest LS score.

WHO recommends at least $150 \mathrm{~min}(2.5 \mathrm{~h})$ per week of PA for older adults (aged 65 years and above) to maintain their physical fitness, which could promote both physical and mental health ${ }^{(17)}$. The precise mechanisms by which PA may promote subjective well-being are yet to be determined. PA may enhance an individual's positive emotions, which are an important element in protecting individuals from illnesses and promoting psychological and physical health ${ }^{(37)}$. PA appears to decrease symptoms of depression, anxiety and tension and improve mood. Findings from previous studies have suggested that PA was positively associated with quality of life in older adults ${ }^{(13,16)}$, where quality of life was assessed by the satisfaction with life scale. In addition, a recent study showed that during leisure time involving in at least mild PA (duration/frequency) was a significant predictor of LS for older adults with a high level of loneliness ${ }^{(38)}$. LS was measured using Likert scale ranging from 1 (strongly disagree) to 7 (strongly agree), answering to the following question ('In most ways, my life is close to ideal'). Our findings showed that sufficient PA according to WHO was associated with higher LS.

Studies on diet quality and LS in older adults are scarce. Mediterranean diet has been associated with lower depression rate in older adults ${ }^{(23)}$. In a young population (17-30 years), LS has been positively associated with higher Mediterranean diet score, non-smoking, physical exercise, eating fruit and limiting fat intake ${ }^{(39)}$. It is necessary to note the differences in the population age and LS assessment scales of previous studies. In community-dwelling Canadian older men, better self-rated health and greater LS were strongly associated with the daily consumption of vegetables and fruits ${ }^{(28)}$. LS was assessed with 
Table 2. Association of Baltic Sea diet (BSD) score and physical activity (PA) with continuous life satisfaction (LS) score ( $\beta$ Coefficients, standard errors and $95 \%$ confidence intervals; mean values and standard deviations)

\begin{tabular}{|c|c|c|c|c|c|}
\hline & $\beta$ & SE & $95 \% \mathrm{Cl}$ & $P_{\text {for trend }}$ & $P_{\text {for trend }}$, adjusted ${ }^{\star}$ \\
\hline BSD score $†$ & -0.016 & 0.03 & $-0.077,0.055$ & 0.729 & 0.673 \\
\hline BSD score quartiles, LS $\ddagger$ & & & & 0.311 & 0.251 \\
\hline \multicolumn{6}{|l|}{ Quartile 1, $n 146$} \\
\hline Mean & $9 \cdot 7$ & & & & \\
\hline SD & $3 \cdot 1$ & & & & \\
\hline \multicolumn{6}{|l|}{ Quartile 2, n125 } \\
\hline Mean & $10 \cdot 4$ & & & & \\
\hline SD & $2 \cdot 8$ & & & & \\
\hline \multicolumn{6}{|l|}{ Quartile 3, $n 129$} \\
\hline Mean & 9.8 & & & & \\
\hline SD & $2 \cdot 9$ & & & & \\
\hline \multicolumn{6}{|l|}{ Quartile 4, $n 107$} \\
\hline Mean & $9 \cdot 4$ & & & & \\
\hline SD & $2 \cdot 4$ & & & & \\
\hline PA (h/week) & -0.207 & 0.37 & $-2.051,-0.568$ & 0.004 & 0.001 \\
\hline PA categories (h/week), LS & & & & 0.035 & 0.015 \\
\hline \multicolumn{6}{|l|}{$\mathrm{PA}=0, n 77$} \\
\hline Mean & $10 \cdot 7$ & & & & \\
\hline SD & 0.53 & & & & \\
\hline \multicolumn{6}{|l|}{$0<\mathrm{PA}<2 \cdot 5, n 166$} \\
\hline Mean & $10 \cdot 3$ & & & & \\
\hline SD & 0.31 & & & & \\
\hline \multicolumn{6}{|l|}{$\mathrm{PA} \geq 2 \cdot 5, n 365$} \\
\hline Mean & $9 \cdot 2$ & & & & \\
\hline SD & 0.20 & & & & \\
\hline BSD and PA interaction & -0.181 & 0.021 & $-0.129,-0.026$ & 0.010 & 0.003 \\
\hline
\end{tabular}

* Analyses were adjusted for age (years) and energy intake $(\mathrm{kJ} / \mathrm{d}), \mathrm{BMl}\left(\mathrm{kg} / \mathrm{m}^{2}\right), \mathrm{PA}(\mathrm{h} /$ week) (only when BSD was set as exposure), years since menopause, smoking status (current smoker), mobility status (normal and restricted), income per month (euros), multi-morbidity and marital status.

† Regression analysis was used to compute $\beta$ coefficients, standard errors and $95 \% \mathrm{Cl}$.

$\ddagger$ Univariate ANOVA was used to compute means and standard deviations.

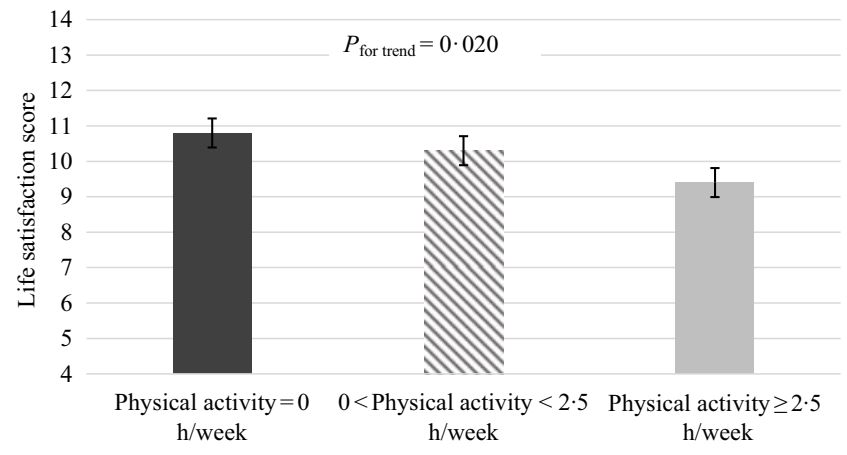

Fig. 1. Life satisfaction score according to physical activity groups. Values are means, with standard deviations represented by vertical bars. Univariate ANOVA adjusted for age (years), total energy intake $(\mathrm{kJ} / \mathrm{d}), \mathrm{BMI}\left(\mathrm{kg} / \mathrm{m}^{2}\right)$, years since menopause, smoking status (current smoker), mobility status, income per month (euros), multi-morbidity and marital status. $P_{\text {for trend }}$ was calculated on a linear trend across physical activity groups using the median value in each group as a continuous variable in a multivariable linear regression analysis with life satisfaction as a continuous dependent variable.

the following question: 'How would you describe your satisfaction with life in general at present?' with a five-point Likert scale ranging from excellent to bad satisfaction. Dietary consumption was estimated with exploratory questions, not with validated measures. In our study, higher BSD score was associated with beneficial health indicators such as less frequent smoking and more PA, but no association with the LS score was observed.

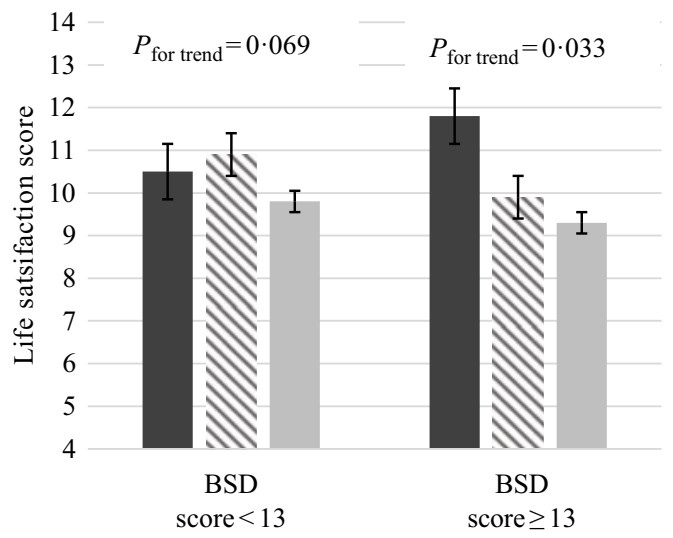

Fig. 2. Stratified association of physical activity (PA) with life satisfaction score according to Baltic Sea diet (BSD) score median value. Values are means, with standard deviations represented by vertical bars. Univariate ANOVA adjusted for age (years), total energy intake $(\mathrm{kJ} / \mathrm{d}), \mathrm{BMl}\left(\mathrm{kg} / \mathrm{m}^{2}\right)$, years since menopause, smoking status (current smoker), mobility status, income per month (euros), multi-morbidity and marital status. $P_{\text {for trend }}$ was calculated on a linear trend across PA groups when analyses were stratified according to the median BSD score $(<13 v . \geq 13)$. The number of women in the groups $(n 510)$ was: $\square, \mathrm{PA}=0 \mathrm{~h} /$ week (BSD $<13, n 9$ and $\mathrm{BSD} \geq 13, n 22) ; \mathrm{N}, 0<\mathrm{PA}<2.5 \mathrm{~h} /$ week $(\mathrm{BSD}<13, n 84$ and $\mathrm{BSD} \geq 13, n 60) ; \quad, \mathrm{PA} \geq 2.5 \mathrm{~h} /$ week $(\mathrm{BSD}<13, n 157$ and $B S D \geq 13, n 158)$.

A healthful diet along with sufficient PA according to WHO recommendations can be the optimal way to promote physical and mental health in older people. One explanation for such an 
association can be that a better diet quality may be an indirect effect of increased health consciousness associated with adoption of regular exercise habit. Our findings suggested a statistically significant interaction between PA and BSD on the LS score. The most advantageous group, that is, those with $\mathrm{PA} \geq 2.5 \mathrm{~h} /$ week and BSD score higher than median (BSD score $\geq 13$ ) were most satisfied with their life. Although further prospective studies are required, this finding can carry a significant public health message that a combination of higher PA and BSD can be linked to the overall satisfaction of life.

Some limitations of the present study are to be considered. The data were initially collected in 2003-2004. Thus, it may be that some aspects of the data collection would not confer totally with current data collection methods, especially for studies with similar hypotheses. For practical reasons, PA questionnaires are currently the most commonly used assessment method in large population-based cohort studies. However, the agreement between different PA questionnaires for correctly revealing individuals as physically active (e.g. meeting the older adult PA recommendations of $>2.5 \mathrm{~h} /$ week) is challenging ${ }^{(40)}$. In addition, a common limitation to this method is overreporting of PA. This might result in an overestimation of subjects to be allocated as sufficiently physically active when PA is assessed with selfreport. Furthermore, although BSD score using computational method has been previously explained ${ }^{(31)}$, computing dietary scores such as BSD using the 3-d food record has limitations as it may not provide complete data on the habitual food consumption as well as the frequency of food consumption. It is noteworthy that energy intake among our study population was relatively low, which may be due to underreporting (conscious or unconscious) or reducing of their typical level of food intake ${ }^{(41)}$. However, none of the participants met the threshold to be excluded from analyses in terms of the basal metabolic rate as explained previously ${ }^{(42)}$. As the participants were relatively young and rather healthy older women from a homogenous Finnish population, generalising the results to the entire older adult population should be done with caution. The present study could not capture temporal changes in the previous years, with respect to long-term diet, quality of life or health status, all of which could affect each other. Data analyses were adjusted for several possible confounders, yet the possibility of residual confounding cannot be excluded.

In conclusion, higher PA among older women may be associated with higher LS both independently and combined with a high BSD score. Studies like this may carry an important public health message that a combination of sufficient PA and a healthful diet quality might have beneficial relationship with the overall LS among older women. However, further longitudinal studies are warranted to increase the knowledge on the role of PA and diet in LS.

\section{Acknowledgements}

The authors would like to thank the participants, secretaries and nurses involved in the present study, with special thanks to Ville Koistinen (Institute of Public Health and Clinical Nutrition, University of Eastern Finland) for proofreading this manuscript.
The OSTPRE-FPS study was supported by the Finnish Cultural Foundation (Hulda Tossavainen Foundation), Sigrid Juselius Foundation, Academy of Finland and Kuopio University Hospital EVO grant. The present study was supported by grants from Finnish cultural foundation, Juho Vainio foundation (201710012) and Otto A. Malm foundation to M. I.

M. I. and A. T. E. had the main responsibility for data analysis, summarising results into tables and figures and writing the manuscript. Further, H. K.-H., D. R. S., R. H., T. R., J. S. and H. K. revised the manuscript for its scientific content.

The authors declare no conflicts of interest.

\section{Supplementary material}

For supplementary material referred to in this article, please visit https://doi.org/10.1017/S000711451900240X

\section{References}

1. World Health Organization (2018) Eurostat. http://ec.europa. eu/eurostat/data/database (accessed June 2019).

2. Hiel L, Beenackers MA, Renders CM, et al. (2015) Providing personal informal care to older European adults: should we care about the caregivers' health? Prev Med 70, 64-68.

3. Diener E \& Chan MY (2011) Happy people live longer: subjective well-being contributes to health and longevity. Appl Psychol Health Well Being 3, 1-43.

4. Chida Y \& Steptoe A (2008) Positive psychological well-being and mortality: a quantitative review of prospective observational studies. Psychosom Med 70, 741-756.

5. Andrews FM \& Withey SB (2012) Social Indicators of Well-being: Americans' Perceptions of Life Quality. New York: Springer Science \& Business Media.

6. Lukkala PS, Honkanen RJ, Rauma PH, et al. (2016) Life satisfaction and morbidity among postmenopausal women. PLOS ONE 11, e0147521.

7. Koivumaa-Honkanen H, Kaprio J, Honkanen R, et al. (2004) Life satisfaction and depression in a 15-year follow-up of healthy adults. Soc Psychiatry Psychiatr Epidemiol 39, 994-999.

8. Koivumaa-Honkanen $\mathrm{H}$, Honkanen $\mathrm{R}$, Viinamäki $\mathrm{H}$, et al. (2000) Self-reported life satisfaction and 20-year mortality in healthy Finnish adults. Am J Epidemiol 152, 983-991.

9. Rissanen T, Viinamäki H, Honkalampi K, et al. (2011) Long term life dissatisfaction and subsequent major depressive disorder and poor mental health. BMC Psychiatry 11, 140.

10. Koivumaa-Honkanen $\mathrm{H}$, Koskenvuo M, Honkanen RJ, et al. (2004) Life dissatisfaction and subsequent work disability in an 11-year follow-up. Psychol Med 34, 221-228.

11. Feller S, Teucher B, Kaaks R, et al. (2013) Life satisfaction and risk of chronic diseases in the European prospective investigation into cancer and nutrition (EPIC)-Germany study. PLOS ONE 8, e73462.

12. Amarantos E, Martinez A \& Dwyer J (2001) Nutrition and quality of life in older adults. J Gerontol A Biol Sci Med Sci 56, 54-64.

13. Rejeski WJ \& Mihalko SL (2001) Physical activity and quality of life in older adults. J Gerontol A Biol Sci Med Sci 56, 23-35.

14. Wikman A, Wardle J \& Steptoe A (2011) Quality of life and affective well-being in middle-aged and older people with chronic medical illnesses: a cross-sectional population based study. PLOS ONE 6, e18952. 
15. Awick EA, Ehlers DK, Aguiñaga S, et al. (2017) Effects of a randomized exercise trial on physical activity, psychological distress and quality of life in older adults. Gen Hosp Psychiatry 49, 44-50.

16. Elavsky S, McAuley E, Motl RW, et al. (2005) Physical activity enhances long-term quality of life in older adults: efficacy, esteem, and affective influences. Ann Behav Med 30, 138-145.

17. World Health Organization (2018) Global Strategy on Diet, Physical Activity and Health. Physical Activity and Older Adults. http://www.who.int/dietphysicalactivity/factsheet_old eradults/en/ (accessed June 2019).

18. Sánchez-Villegas A, Henríquez-Sánchez P, Ruiz-Canela M, et al. (2015) A longitudinal analysis of diet quality scores and the risk of incident depression in the SUN Project. BMC Med 13, 197.

19. Sanchez-Villegas A \& Martínez-González MA (2013) Diet, a new target to prevent depression? BMC Med 11, 3 .

20. Milaneschi Y, Bandinelli S, Corsi AM, et al. (2011) Mediterranean diet and mobility decline in older persons. Exp Gerontol 46, 303-308.

21. Edney LC, Burns NR \& Danthiir V (2015) Subjective well-being in older adults: folate and vitamin $\mathrm{B}_{12}$ independently predict positive affect. Br J Nutr 114, 1321-1328.

22. Rienks J, Dobson AJ \& Mishra GD (2013) Mediterranean dietary pattern and prevalence and incidence of depressive symptoms in mid-aged women: results from a large community-based prospective study. Eur J Clin Nutr 67, 75.

23. Skarupski KA, Tangney CC, Li H, et al. (2013) Mediterranean diet and depressive symptoms among older adults over time. J Nutr Health Aging 17, 441-445.

24. Lengyel CO, Tate RB \& Obirek Blatz AK (2009) The relationships between food group consumption, self-rated health, and life satisfaction of community-dwelling Canadian older men: the Manitoba follow-up study. J Nutr Elder 28, 158-173.

25. Hodge A \& Bassett J (2016) What can we learn from dietary pattern analysis? Public Health Nutr 19, 191-194.

26. Kanerva N, Kaartinen NE, Schwab U, et al. (2013) Adherence to the Baltic Sea diet consumed in the Nordic countries is associated with lower abdominal obesity. Br J Nutr 109, 520-528.

27. Ruusunen A, Lehto SM, Tolmunen T, et al. (2013) Adherence to the Baltic sea diet is associated with lower prevalence of elevated depressive symptoms. Eur Psychiatry 28, Suppl. 1, article 735.

28. Salovaara K, Tuppurainen M, Kärkkäinen M, et al. (2010) Effect of vitamin $\mathrm{D}_{3}$ and calcium on fracture risk in 65- to 71-year-old women: a population-based 3-year randomized, controlled trial-the OSTPRE-FPS. J Bone Miner Res 25, 1487-1495.

29. Erkkilä AT, Jarvinen R, Karvonen H, et al. (2012) Validation of a semi-quantitative FFQ using food records as a reference in older women in the Kuopio Fracture Prevention Study (OSTPRE-FPS). Public Health Nutr 15, 635-639.

30. Isanejad M, Sirola J, Mursu J, et al. (2018) Association of the Baltic Sea and Mediterranean diets with indices of sarcopenia in elderly women, OSPTRE-FPS study. Eur J Nutr 57, 1435-1448.

31. Koivumaa-Honkanen H, Honkanen R, Viinamaeki $\mathrm{H}$, et al. (2001) Life satisfaction and suicide: a 20-year follow-up study. Am J Psychiatry 158, 433-439.

32. Koivumaa-Honkanen $\mathrm{H}$, Viinamäki $\mathrm{H}$, Honkanen $\mathrm{R}$, et al. (1996) Correlates of life satisfaction among psychiatric patients. Acta Psychiatr Scand 94, 372-378.

33. Andrews FM \& Withey SB (1976) Social Indicators of WellBeing: Americans' Perception of Life Quality. New York: Plenum.

34. Campbell A, Converse PE \& Rodgers WL (1976) The Quality of American Life. New York: Russell Sage Foundation.

35. Allardt E \& Uusitalo H (1972) Dimensions of welfare in a comparative study of the Scandinavian societies. Scand Polit Stud 7, 9-27.

36. Kärkkäinen M, Tuppurainen M, Salovaara K, et al. (2010) Effect of calcium and vitamin D supplementation on bone mineral density in women aged 65-71 years: a 3-year randomized population-based trial (OSTPRE-FPS). Osteoporos Int 21, 2047-2055.

37. Zhu YY \& Mao ZM (2008) Application study of UNIANOVA and linear in SPSS. Comput Eng Des 29, 2108-2110.

38. Fredrickson BL \& Joiner T (2002) Positive emotions trigger upward spirals toward emotional well-being. Psychol Sci 13, $172-175$.

39. Kim J, Lee S, Chun S, et al. (2017) The effects of leisure-time physical activity for optimism, life satisfaction, psychological well-being, and positive affect among older adults with loneliness. Ann Leis Res 20, 406-415.

40. Grant N, Wardle J \& Steptoe A (2009) The relationship between life satisfaction and health behavior: a cross-cultural analysis of young adults. Int J Behav Med 16, 259-268.

41. Steene-Johannessen J, Anderssen SA, Van der Ploeg HP, et al. (2016) Are self-report measures able to define individuals as physically active or inactive? Med Sci Sports Exerc 48, 235.

42. Lührmann PM, Herbert BM, Gaster C, et al. (1999) Validation of a self-administered 3-day estimated dietary record for use in the elderly. Eur J Nutr 38, 235-240.

43. Isanejad M, Mursu J, Sirola J, et al. (2016) Dietary protein intake is associated with better physical function and muscle strength among elderly women. Br J Nutr 115, 1281-1291. 